\title{
Lexicalizing disjunction scope
}

\author{
Virginia Dawson*
}

\begin{abstract}
Tiwa (Tibeto-Burman; India) has two disjunctive particles, which give rise to different interpretations in sentences with other operators. I argue that this semantic distinction is not one of inclusive vs. exclusive disjunction, but one of scope. I provide an analysis that captures this scopal distinction: one particle lexicalizes a choice function variable (subject to existential closure high in the structure), and the other lexicalizes an alternative-set former which interacts with higher operators. I also show that wide scope disjunction in Tiwa behaves differently from wide scope readings of English or, and suggest that they warrant different analyses.
\end{abstract}

Keywords. disjunction; scope; choice functions; alternatives; semantic variation; Tiwa

1. Introduction. Tiwa, a Tibeto-Burman language of India, is one of various languages that have more than one way of expressing disjunction. ${ }^{1}$ For instance, the English sentence in (1) can be expressed in Tiwa with the disjunctive particle khi as in (1-a), or with the disjunctive particle $b a$ as in $(1-b){ }^{2}$

(1) 'Lastoi will come tomorrow or the day after.'

a. Lastoi [ khónana khí sónena ] phi-w.

Lastoi tomorrow or day.after come-NEUT

b. Lastoi [ khónana ba sónena ] phi-w.

Lastoi tomorrow or day.after come-NEUT

While these two disjunctions are logically equivalent in cases like (1), differences arise when there is another operator in the clause. This is illustrated with clausemate negation in (2). In (2-a), the particle khí is used. This sentence conveys that Sonali either didn't meet Mansing, or she didn't meet Milton (but perhaps the speaker cannot remember who). It cannot convey that Sonali met neither of them. In contrast, (2-b) uses the particle $b a$. This sentence must convey that Sonali met neither; it cannot convey that she met one but not the other.

* Thanks to Mary Maslai, Bibiana Maslai, Pilsing Malang, and the rest of the Tiwa community at Umswai for sharing their language with me. Thanks also to Amy Rose Deal, Line Mikkelsen, Peter Jenks, Seth Yalcin, and audiences at UC Berkeley, CUSP 11 and LSA 2019 for comments and feedback on various parts of this work. Author: Virginia Dawson, University of California, Berkeley (virginia.dawson@ berkeley.edu).

${ }^{1}$ Other examples include Latin aut vs. vel, French ou vs. soit soit (Spector 2014; Nicolae 2017), and Sinhala -hari vs. - $d a$ (Weerasooriya 2017).

${ }^{2}$ Examples are given in the orthography of Joseph's 2014 dictionary. Glossing conventions are: ACC 'accusative', ADD 'additive', ALL 'allative', ANAPH 'anaphor', AUX 'auxiliary', COMP 'complementizer', COND 'conditional', GEN 'genitive', INF 'infinitive', IPFV 'imperfective', NEG 'negation', NEUT 'neutral aspect', NMLZ 'nominalizer', PFV 'perfective', PL 'plural', PST 'past'. 
(2) 'Sonali didn't meet Mansing or Milton.'

a. Sonali [ Mansing khí Milton ] -go lak mán-ya-m.

Sonali Mansing or Milton -ACC meet-NEG-PST

$\checkmark$ Either Sonali didn't meet Mansing, or she didn't meet Milton, (but the speaker can't remember who.)

$\boldsymbol{X}$ Sonali met neither Mansing nor Milton.

b. Sonali [ Mansing ba Milton ] -go lak mán-ya-m.

Sonali Mansing or Milton -ACC meet-NEG-PST

$x$ Either Sonali didn't meet Mansing, or she didn’t meet Milton, (but the speaker can't remember who.)

$\checkmark$ Sonali met neither Mansing nor Milton.

Distinct strategies of disjunction like these are sometimes thought to reflect a distinction between inclusive and exclusive disjunction (see, e.g., Weerasooriya 2017 on Sinhala). However, we know that disjunction is a scope-taking element (Rooth \& Partee 1982, Larson 1985, Winter 2002, a.o.). For example, English or, an inclusive disjunctor, gives rise to two distinct readings when embedded under clausemate negation as in (3); these reflect the two options for relative scope of the disjunction and clausal negation.

(3) Amelia didn't see a red robin or a magpie.

a. $\neg$ [Amelia saw a red robin $\vee$ Amelia saw a magpie $] \quad \neg>\vee$

Amelia saw neither a red robin nor a magpie.

b. $\quad[\neg[$ Amelia saw a red robin $]] \vee[\neg[$ Amelia saw a magpie $]] \quad \vee>\neg$ Amelia didn't see a red robin, or she didn't see a mapgie. (I can't remember which.)

The narrow scope reading of or is represented in (3-a). Here, negation outscopes disjunction, which gives rise to the reading that Amelia saw neither a red robin nor a magpie. In (3-b) by contrast, disjunction outscopes negation, giving rise to the reading in which Amelia either didn't see a red robin, or she didn't see a magpie. This reading is made particularly salient with the follow-up but I can't remember which.

In this paper, I argue that Tiwa's two disjunction strategies are an instance of lexicalized disjunction scope, and present an analysis that captures these facts: $k$ hi lexicalizes a choice function variable that is existentially closed high (cp. Winter 2002, Schlenker 2006), while ba disjunctions denote a set of Hamblin-style alternatives which are quantified over by operators higher in the structure (cp. Simons 2005, Alonso-Ovalle 2006, Aloni 2007). I also show that this scope distinction is different from the scopal ambiguity found in English, suggesting that wide scope readings of disjunction have different sources across languages.

The paper is structured as follows. In $\S 2$ I argue that the distinction between $k h i$ and $b a$ cannot be one of inclusive vs. exclusive disjunction, but must be one of scope. In $\S 3$ I provide the core data showing this scopal distinction across a range of operators and syntactic contexts. In $\S 4$ and $\S 5$ I turn to the analysis of khi and $b a$ respectively, highlighting a key difference between wide scope English or and khí. $\S 6$ concludes and lays out some cross-linguistic prospects. 
2. Not $\{\mathbf{i n} / \mathbf{e x}\}$ clusivity. Tiwa is a Tibeto-Burman language spoken by approximately 27,100 people primarily in Assam, India. ${ }^{3}$ The data throughout come from original fieldwork in Umswai, Assam between 2016 and 2018, primarily from extensive work with one consultant with supporting data from two additional speakers. The crucial scope data were elicited through speaker judgments in context, according to the methodology laid out in Matthewson 2004. Judgments were replicated across years and across speakers.

The readings that khí disjunction receives are often reminiscent of exclusive disjunction. For instance, $k h i$ disjunction in the antecedent of a conditional is judged felicitous only if exactly one of the disjuncts holds, as shown in (4).

(4) [ Mukton khí Monbor ] phi-gaido, Saldi khâdu-gam.

Mukton or Monbor come-COND Saldi happy-MODAL

'If Mukton or Monbor comes, Saldi would be happy.'

$\checkmark$ Saldi is in love with either Mukton or Monbor, but we don't know who. Whoever it is, she'll be happy if he comes to visit.

$X$ Saldi is in love with both Mukton and Monbor. She will be happy if either of them comes.

An initial hypothesis about the difference in meaning between $k h i$ and $b a$ could be that khi encodes exclusive disjunction, while $b a$ encodes the familiar inclusive disjunction. This hypothesis is represented in (5).

(5) Clusivity hypothesis: $\llbracket k h i ́ \rrbracket=\underline{\vee}, \llbracket b a \rrbracket=\vee$

The clusivity hypothesis makes a prediction about how the two disjunctions should behave under the scope of negation. Specifically, if khí encodes exclusive disjunction, it should, when embedded under negation, yield truth in two distinct scenarios. That is, if an exclusive disjunction returns true if exactly one of the disjuncts is true, the negation of an exclusive disjunction should return true if (a) neither disjunct is true, or (b) both disjuncts are true. Recall that inclusive disjunction under negation will only return true if neither disjunct is true.

This prediction is testable in Tiwa in biclausal environments. While khí disjunction must scope above clausemate negation (as in (2) above), it can scope beneath negation in a higher clause.(More generally, khi disjunction can scope at the edge of a finite clause, a fact which is discussed in more detail in $\S 3$ below.) This is shown in (6), in which a khí disjunction is inside a finite $\mathrm{CP}$ embedded under negation in the matrix clause. This sentence is felicitous in a context in which the speaker believes that neither disjunct is true, showing that it can scope under higherclausal negation.

(6) [CP [ Saldi khí Lastoi ] Guwahati-jíng lí-ga honmandé ] thangane cha. Pibúr sáning-bô Saldi or Lastoi Guwahati-ALL go-PFV COMP correct NEG 3PL two-ADD lí-ya-m. go-NEG-PST

'It's not correct that Saldi or Lastoi went to Guwahati. They both didn't go.'

$\checkmark$ Someone has asserted that Saldi and Lastoi went to Guwahati. The speaker disagrees; she knows that neither of them went.

\footnotetext{
${ }^{3}$ This population estimate is from the 2001 Indian census, as reported in Ethnologue (Simons \& Fennig 2017).
} 
The example in (6) is compatible with either an inclusive or an exclusive analysis of khí. (7) presents the crucial test case. Here, we see another instance of khi disjunction embedded under higher-clausal negation. However, this sentence is judged infelicitous in a context in which both disjuncts hold, which is unexpected under an exclusive disjunction analysis. As the speaker's comment indicates, this sentence receives the interpretation that neither disjunct holds. (8) provides another example showing that negated $k h i$ disjunction is not judged felicitous if both disjuncts hold.

[CP Mansing [ rojá-ga khí misâ-ga ] honmandé ] thángane cha. Mansing sing-PFV or dance-PFV COMP correct NEG

'It's not correct that Mansing sang or danced.'

$\boldsymbol{X}$ At the festival, Mansing sang and he danced.

Speaker comment: "He didn't do either."

[CP [ Mukton khí Lastoi ] hat-jíng lí-ga honmandé ] thángane cha.

Mukton or Lastoi market-ALL go-PFV COMP correct NEG

'It's not correct that Mukton or Lastoi went to market.'

$\boldsymbol{x}$ Mukton and Lastoi both went to market.

I conclude from these data that khí disjunction is inclusive, and that the difference between $k h^{\prime} l$ and $b a$ disjunction observed in (2) is one of scope. I assume that any exclusivity and ignorance effects associated with $k h i$ (as well as with $b a$ ) arise as implicatures through competition with conjunction and the individual disjuncts in the familiar way (see Sauerland 2004 and Fox 2007).

3. Lexicalization of disjunction scope. In the introduction, we saw that khi disjunction necessarily takes wide scope with respect to clausemate negation, and $b a$ necessarily takes narrow scope. This pattern holds more generally: khí must take wide scope with respect to any other clausemate operator (Dawson 2018b), and ba must take narrow scope with respect to these same operators. This is illustrated for a universal quantifier in (9). In these examples the disjunction is in the restrictor to the universal quantifier. When khi disjunction is used, the sentence conveys that Lastoi either loves every boy or she loves every girl; it cannot convey that she loves both (i.e., with the universal quantifying over the Boolean join of boys and girls). Note that just as wide scope readings of English disjuction give rise to exclusivity inferences, so too does khí disjunction. When $b a$ disjunction is used, we see the reverse.

(9) 'Lastoi loves all the boys or girls.'

a. Lastoi [DP sógol [ mewâ-raw khí margî-raw ] -go ] han sha-w. Lastoi every boy-PL or woman-PL -ACC love-NEUT $\checkmark$ I know that Lastoi loves only the boys or only the girls, but I can't remember which. $x$ Lastoi loves everyone. She loves all the boys and all the girls.

b. Lastoi [DP sógol [ mewâ-raw ba margî-raw ] -go ] han sha-w. Lastoi every boy-PL or woman-PL -ACC love-NEUT $\boldsymbol{X}$ I know that Lastoi loves only the boys or only the girls, but I can't remember which. $\checkmark$ Lastoi loves everyone. She loves all the boys and all the girls.

A similar pattern holds for disjunction scope with respect to the comparative operator, as shown in (10). When a khi disjunction is used in the standard of comparison, the sentence conveys that 
the subject is taller than Tonbor, or he is taller than Lastoi; it cannot convey that he is taller than both (i.e., with the comparative operator taking the maximal degree of height of either of Tonbor or Lastoi). Again, $b a$ disjunction conveys the opposite.

(10) 'Mukton is taller than Tonbor or Lastoi.'

a. Mukton [ Tonbor khí Lastoi ] -na khúli parâ chu-w.

Mukton Tonbor or Lastoi -DAT than more tall-NEUT

$\checkmark$ Mukton is taller than Tonbor, or he's taller than Lastoi, but we can't remember which.

$\boldsymbol{x}$ Mukton is taller than both Tonbor and Lastoi.

b. Mukton [ Tonbor ba Lastoi ] -na khúli parâ chu-w.

Mukton Tonbor or Lastoi -DAT than more tall-NEUT

$\boldsymbol{x}$ Mukton is taller than Tonbor, or he's taller than Lastoi, but we can't remember which.

$\checkmark$ Mukton is taller than both Tonbor and Lastoi.

Likewise, $k h i$ takes wide scope with respect to intensional operators, while $b a$ takes narrow scope. This is shown for a possibility modal in (11), and the intensional verb as hóng 'want' in (12). Under the possibility modal, khí conveys that the subject is allowed to drink tea, or she is allowed to drink coffee - it cannot convey that she has a choice between the two - while ba conveys the opposite. Similarly, in (12), khi conveys that the subject wants to meet the prime minister, or she wants to meet the president; it cannot convey that she wants to meet either of them. In contrast, $b a$ can only convey that she would be happy to meet either.

(11) 'Saldi can drink tea or coffee.'

a. Saldi [ sa khí coffee ] -go nung-a phon-o.

Saldi tea or coffee -ACC drink-INF can-NEUT

$\checkmark$ Saldi is allowed to drink tea, but not coffee, (but we can't remember which one it is.)

$x$ Saldi is allowed to drink tea and she's allowed to drink coffee; it's her choice which.

b. Saldi [ sa ba coffee ] -go nung-a phon-o.

Saldi tea or coffee -ACC drink-INF can-NEUT

$x$ Saldi is allowed to drink tea, but not coffee, but we can't remember which one it is.

$\checkmark$ Saldi is allowed to drink tea and she's allowed to drink coffee; it's her choice which.

(12) 'Lastoi wants to meet the prime minister or the president.'

a. Lastoi [ PM khí president ] -go lak mán-a as hóng-do.

Lastoi PM or president -ACC meet-INF want-IPFV

$\checkmark$ Lastoi hates Modi (the PM), and never wants to meet him, but she does want to meet the president. We can't remember who she hates and who she wants to meet.

$x$ Lastoi is very interested in politics. It's her dream to meet the PM or the president of India. If she could meet either one, she would be very happy. 
b. Lastoi [ PM ba president ] -go lak mán-a as hóng-do.

Lastoi PM or president -ACC meet-INF want-IPFV

$x$ Lastoi hates Modi (the PM), and never wants to meet him, but she does want to meet the president. We can't remember who she hates and who she wants to meet.

$\checkmark$ Lastoi is very interested in politics. It's her dream to meet the PM or the president of India. If she could meet either one, she would be very happy.

So far we have seen that khi must take wide scope with respect to all other operators in its finite clause. (Note that just like in English, as hóng 'want' selects a non-finite infinitival complement.) We saw in $\S 2$ above that khi can, however, scope at the edge of its finite clause, beneath negation in the matrix clause. This fact holds more generally for khi dsjunctions in embedded finite clauses. For example, khí can also scope beneath attitude verbs that select for finite $\mathrm{CP}$ complements, such as $s i$ 'know', as shown in (13). Here, there is a khi dsjunction inside the embedded CP complement. This disjunction is interpreted under the scope of the attitude verb; it is Lastoi who holds the belief that Mukton or Tonbor took the book.

(13) Lastoi si-ga, [CP [ Mukton khí Tonbor ] lái-gô lang lí-ga honmandé. ]

Lastoi know-PFV Mukton or Tonbor book-ACC take AUX-PFV COMP

'Lastoi knows that Mukton or Tonbor took the book.'

$\checkmark$ Lastoi knows that either Mukton or Tonbor took the book, but she's not sure which one. I know who it was, but I haven't told her.

The fact that khí scopes at the edge of its finite clause might initially be taken as evidence that $k h i$ is island-bound in its scopal interpretation. However, khi must scope out of non-finite scope islands. Just like in English, conditional antecedents and relative clauses are scope islands in Tiwa (Dawson 2018a), but in contrast to English, these environments are non-finite. Khí disjunction must take wide scope from within both these environments. This is shown for a conditional in (14). Here, the verb in the conditional antecedent is marked with conditional morphology, but (unlike in English) not inflected for tense or aspect. The khí disjunction in the antecedent must take wide scope over the conditional. As expected, ba disjunction must take narrow scope. ((14-a) is repeated from (4) in $\S 2$ above.)

(14) 'If Mukton or Monbor comes, Saldi would be happy.'

a. [ Mukton khí Monbor ] phi-gaido, Saldi khâdu-gam.

Mukton or Monbor come-COND Saldi happy-MODAL

$\checkmark$ Saldi is in love with either Mukton or Monbor, but we don't know who. Whoever it is, she'll be happy if he comes to visit.

$x$ Saldi is in love with both Mukton and Monbor. She will be happy if either of them comes.

b. [ Mukton ba Monbor ] phi-gaido, Saldi khâdu-gam.

Mukton or Monbor come-COND Saldi happy-MODAL

$x$ Saldi is in love with either Mukton or Monbor, but we don't know who. Whoever it is, she'll be happy if he comes to visit.

$\checkmark$ Saldi is in love with both Mukton and Monbor. She will be happy if either of them comes. 
Similar facts hold for khí disjunction in relative clauses. As the examples in (15) show, relative clauses in Tiwa also lack tense and aspect inflection; they are non-finite nominalized clauses. In (15-a), the khí disjunction must scope above the intensional matrix verb from its position within a relative clause. In contrast, $b a$ must take narrow scope, as shown in (15-b).

'Lastoi is looking for a book that Lastoi or Mukton read.'

a. Saldi [DP [RC [ Lastoi-ne khí Mukton-e ] lekhé-wa ] lái-gô ] pishár-do. Saldi Lastoi-GEN or Mukton-GEN read-NMLZ book-ACC search-IPFV $\checkmark$ Saldi is looking for a book in the library. She wants one that Mukton read, or she wants one that Lastoi read, but I can't remember which.

$x$ Saldi is looking for a book in the library. She'd be happy with one that Mukton read and she'd be happy with one Lastoi read.

b. Saldi [DP [RC [ Lastoi-ne ba Mukton-e ] lekhé-wa ] lái-gô ] pishár-do. Saldi Lastoi-GEN or Mukton-GEN read-NMLZ book-ACC search-IPFV $x$ Saldi is looking for a book in the library. She wants one that Mukton read, or she wants one that Lastoi read, but I can't remember which.

$\checkmark$ Saldi is looking for a book in the library. She'd be happy with one that Mukton read and she'd be happy with one Lastoi read.

In summary, khí disjunction must take wide scope over any other operator within its finite clause, including from within scope islands. It may, however, scope beneath operators in higher clauses. $B a$ disjunction, in contrast, always takes narrow scope. In the next two sections, we turn to the analysis of khi and ba disjunction that accounts for these facts.

4. Capturing wide scope disjunction. Wide scope readings of or show clear parallels to wide scope readings of indefinites in English. Analyses have drawn on these parallels by assigning a uniform analysis to wide scope disjunctions and wide scope indefinites (e.g. Rooth \& Partee 1982, Schlenker 2006, Brasoveanu \& Farkas 2011, Charlow 2014). There is clear morphological support in Tiwa for this connection: wide scope indefinites are also formed with khíA An example is given in (16), in which the khí indefinite indakhí must take wide scope with respect to clausemate negation. Just like khí disjunction, khí indefinites take obligatory wide scope with respect to all other operators (see Dawson 2018a).

Maria inda-khí kashóng pre-ya-m.

Maria what-KHI dress buy-NEG-PST

'Maria didn't buy some dress.'

$\checkmark$ Maria went to market, and she bought all of the dresses except for one. $\quad \exists>\neg$

$x$ Maria went to market and bought many things, but she didn't buy dresses because there were none.

Winter (2002) and Schlenker (2006) propose that wide scope readings of disjunction are derived via choice functions, which provide a way of deriving obligatory wide existential scope, including from inside islands. ${ }^{4}$ (This is not the only option for deriving exceptional wide scope on the market, but for reasons that will become clear below it is well suited to the Tiwa data.) Following these

\footnotetext{
${ }^{4}$ See Reinhart 1997, Winter 1997, Kratzer 1998, and Matthewson 1999.
} 
approaches, I propose that khí introduces a choice function variable that ranges over the set of the two disjuncts, as in (17).

$$
\llbracket \alpha \text { khí } \beta \rrbracket=\mathrm{f}(\{\alpha, \beta\}) \text {, where } \mathrm{f} \text { is a } \mathrm{CF}
$$

I further propose that this choice function variable is subject to existential closure at the edge of a finite clause. This existential closure ensures widest scope out of non-finite environments such as conditional antecedents and relative clauses, but also allows for narrow scope with respect to operators in higher clauses (e.g. in examples (6) and (13) above). An example of how this analysis works for clausemate negation is presented in (18-b): a choice function variable ranges over the disjunction, interpreted in situ, with existential closure of this variable occuring above negation.

$$
\begin{aligned}
& \text { a. Sonali [ Mansing khí Milton ] -go lak mán-ya-m. } \\
& \text { Sonali Mansing or Milton -ACC meet-NEG-PST } \\
& \text { 'Sonali didn't see Mansing or Milton.' } \\
& \text { b. } \exists \mathrm{f}[\mathrm{CH}(\mathrm{f}) \& \neg[\text { Sonali met } \mathrm{f}(\{\text { Mansing, Milton }\})]]
\end{aligned}
$$

Because the disjunction is interpreted in situ, with the choice function variable existentially closed at the edge of the finite clause, disjunctions in non-finite islands such as conditional antecedents are predicted to take wide scope from within the island:
a. [ Mukton khí Monbor ] phi-gaido, Saldi khâdu-gam.
Mukton or Monbor come-COND Saldi happy-MODAL
'If Saldi meets Mukton or (if she meets) Monbor, she'll be happy.'
b. $\exists \mathrm{f}[\mathrm{CH}(\mathrm{f}) \&$ [Saldi meets $\mathrm{f}(\{$ Mukton, Monbor $\}) \rightarrow$ Saldi is happy]]

Choice functional analyses of English wide scope indefinites and disjunction like the one above have faced problems in certain environments (Chierchia 2001, Schwarz 2001, Charlow 2014). Specifically, a choice functional approach overpredicts wide scope readings in downward entailing contexts where there is a bound pronoun in the disjunct. (Brasoveanu \& Farkas (2011) call the absence of this reading the Binder Roof Constraint.) For instance, a choice functional analysis predicts the sentence in (20-a) should have a reading corresponding to the truth conditions in (20-b). That is, it should be true so long as there is some way of selecting from among each candidate's vitas and portfolios, such that that candidate didn't submit whatever is selected. For instance, the sentence should be true if some candidates submitted their vitas, but not their portfolios, and some submitted their portfolios, but not their vitas, and, crucially, nobody submitted both. (20-a) does not have that reading; it is only true in a scenario in which each candidate submitted neither. The choice functional analysis overgenerates wide-scope readings for English.

(20) Binder Roof Constraint in English (example based on Charlow 2014):

a. No candidate submitted her $_{i}$ vita or her portfolio. .

$x$ Candidate A submitted her vita, but not her portfolio. Candidates B and C submitted their portfolios, but not their vitas. No candidate submitted both.

$\checkmark$ No candidate submitted her vita, and no candidate submitted her portfolio.

b. Choice function analysis incorrectly predicts:

$\exists \mathrm{f}[\mathrm{CH}(\mathrm{f}) \& \neg \exists \mathrm{x}[\mathrm{x}$ submitted $\mathrm{f}(\{\mathrm{x}$ 's vita, x’s portfolio $\})]]$ 
Khí disjunction does not face this overgeneration problem. That is, khí disjunctions with bound pronouns in downward-entailing environments give rise to exactly the reading that the choice func-tional analysis predicts. This is shown in (21-a), which has the predicted readings in (21-b). Unlike its English translation (which is misleading), the Tiwa sentence is judged true in a situation in which some students did their math homework, others did their science homework, but nobody did both. In contrast to comparable English sentences, it completely lacks the narrow scope reading.(This fact is unsurprising, given that clausemate narrow scope readings of khi are ruled out more generally.) Similarly, the Tiwa sentence in (22-a) has the reading predicted by the choice functional analysis in (22-b).

(21) No Binder Roof Constraint in Tiwa:

a. Sharbo $_{i}\left[\begin{array}{llll}\text { othê }_{i} & \text { kurikha kam-go khí othê } & \text { sorjon munthuri kam-go ] }\end{array}\right.$ nobody ANAPH math work-ACC or ANAPH science work-ACC chol-ya-m.

do-NEG-PST

'Nobody ${ }_{i}$ did his/her ${ }_{i}$ math HW or his/her ${ }_{i}$ science HW.'

$\checkmark$ Mukton, Tonbor, and Mansing did almost all their school work. Mukton didn't do his math homework (but he did his science), and Tonbor and Mansing didn't do their science homework (but they did their math).

$\boldsymbol{x}$ Nobody did any homework.

b. Choice function analysis correctly predicts:

$\exists \mathrm{f}[\mathrm{CH}(\mathrm{f}) \& \neg \exists \mathrm{x}[\mathrm{x}$ did $\mathrm{f}(\{\mathrm{x}$ 's math HW, x's science $\mathrm{HW}\})]]$

a. Sharbo $_{i}$ [ othê $\hat{i}_{i}$ ta-wa kashóng-go khí othê $\hat{e}_{i}$ ta-wa pháskai-gô ] nobody ANAPH weave-NMLZ kashong-ACC or ANAPH weave-NMLZ phaskai-ACC phál-a as hóng-ya-m.

sell-INF want-NEG-PST

'Nobody ${ }_{i}$ wanted to sell the kashóng that she ${ }_{i}$ wove or the pháskai that $\mathrm{she}_{i}$ wove.' $^{\prime}$

$\checkmark$ Saldi, Sonali and Lastoi each wove many kashóng and pháskai. Each woman was planning to sell all the things they wove, but when the time came they did not want to sell them all. Each woman kept one: Lastoi kept her pháskai, Sonali kept her kashóng, and Lastoi also kept her kashóng.

b. Choice function analysis correctly predicts:

$\lambda \mathrm{w} . \exists \mathrm{f}[\mathrm{CH}(\mathrm{f}) \& \neg \exists \mathrm{x}[\forall \mathrm{w}$ ' $\in \mathrm{BOUL}(\mathrm{x}, \mathrm{w})[\mathrm{x}$ sells $\mathrm{f}(\{\mathrm{x}$ 's kashong, x's phaskai $\})$ in w']]

These data show that a choice functional analysis makes the right predictions for khi disjunction in Tiwa. They also show that wide scope disjunction in Tiwa and English behave differently. I return to this point in $\S 6$.

5. Capturing narrow scope disjunction. The analysis of khi disjunction above involves alternatives: the choice function ranges over a set of alternatives made up of the individual disjuncts. Disjunction can and has also been treated as alternative-denoting without choice functions. In this section, I argue for this analysis for narrow scope $b a$ disjunction.

An alternatives approach has advantages over a Boolean analysis of disjunction in deriving 
free choice readings under modals (Simons 2005, Alonso-Ovalle 2006, Aloni 2007). The problem the Boolean approach faces is that if or denotes the Boolean join, which returns true so long as one of the disjuncts makes the proposition true, $\diamond[\mathrm{p} \vee \mathrm{q}]$ should be true even if $\diamond \mathrm{p} \wedge \neg \vee \mathrm{q}$. As (23) shows, this is not the case.

Khaleda can eat a banana or candy.

$\boldsymbol{X}$ Khaleda can eat a banana, but she cannot eat candy.

In contrast, under an alternatives-based approach, the modal operator can have access to both disjuncts separately (see Simons 2005, Alonso-Ovalle 2006 and Aloni 2007). Tiwa's ba disjunction behaves identically to English or in this respect: (24) is not judged true when only one disjunct holds.

(24) Saldi [ sa ba coffee ] -go nung-a phon-o.

Saldi tea or coffee -ACC drink-INF can-NEUT

'Saldi can drink tea or coffee.'

$\boldsymbol{X}$ Saldi is allowed to drink tea, but not coffee.

This fact suggests an alternative-based analysis rather than a Boolean one is preferable for Tiwa (as it is for English). Following such approaches, I propose that $b a$ disjunctions simply denote the set made up of the individual disjunctions, as in (25).

$$
\llbracket \alpha \text { ba } \beta \rrbracket=\{\alpha, \beta\}
$$

These alternatives compose pointwise with other material in the structure until they are quantified over by an operator, deriving narrow scope. This can be cast in a Hamblin-style system, in which (almost) all other material denotes a singleton set containing its regular denotation. Pointwise function application yields a set that contains the output of function application of each member of one set with each member of the other set. (This process will be illustrated in (29) below). If no operator quantifies over the alternatives, the set of propositions is existentially closed, yielding a disjunctive reading in which at least one of the propositions is true.

This approach requires a slight update in the semantics of the operators to handle the alternatives. Specifically, the operators will need to universally quantify over the alternatives. This update is shown for negation in (26) and universal quantification in (27). Both operators take in a set of alternatives (propositions for NEG and properties for 'every'), and apply to each alternative in that set. Other operators can be defined similarly.

$\llbracket$-ya 'NEG' $=\lambda \alpha . \forall \mathrm{p}[\mathrm{p} \in \alpha \rightarrow \neg \mathrm{p}]$, where $\alpha$ is a non-empty set of propositions

【sógol 'every' $\rrbracket=\lambda \alpha \cdot \lambda \beta . \forall \mathrm{x}[[\forall \mathrm{P} \in \alpha \rightarrow \mathrm{P}(\mathrm{x})] \rightarrow[\forall \mathrm{Q} \in \beta \rightarrow \mathrm{Q}(\mathrm{x})]]$, where $\alpha$ and $\beta$ are non-empty sets of properties

Because the operators quantify over the alternatives, $b a$ 's narrow scope is ensured. This is shown for clausemate negation, repeated in (28) from the introduction, in (29) and (30).

(28) Sonali [ Mansing ba Milton ] -go lak mán-ya-m.

Sonali Mansing or Milton -ACC meet-NEG-PST

'Sonali saw neither Mansing nor Milton.' 
The disjunction itself denotes the set of Mansing and Milton, as in (29-a). This set composes with the verb, which denotes a singleton set containing its regular denotation (29-b), to create a set of properties (29-c), which in turn composes with the subject to form a set of propositions (29-e).

Pointwise function application:

a. $\llbracket$ Mansing ba Milton-go $\rrbracket=\{$ Mansing, Milton $\}$

b. $\llbracket$ lak mán $\rrbracket=\{\lambda \mathrm{x} . \lambda \mathrm{y} . \mathrm{y}$ met $\mathrm{x}\}$

c. 【Mansing ba Milton-go lak mán $\rrbracket=\{\lambda y . y$ met Mansing, $\lambda y$. y met Milton $\}$

d. $\llbracket$ Sonali $\rrbracket=\{$ Sonali $\}$

e. 【Sonali Mansing ba Milton-go lak mán $\rrbracket=\{$ Sonali met Mansing, Sonali met Milton $\}$

This set of propositions then composes with negation, resulting in the truth conditions in (30): for each proposition in the set, the negation of that proposition holds.

(30) Quantifying over alternatives:

$\llbracket$ Sonali Mansing ba Milton-go lak mán-ya $\rrbracket=\forall p[p \in\{$ Sonali met Mansing, Sonali met Milton $\} \rightarrow \neg$ p]

Crucially, this analysis derives narrow scope only: any operator that is higher in the structure than a $b a$ disjunction will necessarily quantify over the alternatives that the $b a$ disjunction denotes. ${ }^{5}$ Importantly, this update in the semantics of the operators (and the shift to a Hamblin semantics) does not affect the choice functional analysis of khí. While khí disjunction involves alternatives, these alternatives are dealt with by the choice function. In a Hamblin system, a khí disjunction would denote a singleton set, as in (31-a).

(31) Khí in a Hamblin semantics:

a. 【Mansing khí Milton-go $\rrbracket=\{\mathrm{f}(\{$ Mansing, Milton $\})\}$

b. 【Sonali Mansing khí Milton-go lak mán》 $=\{$ Sonali met $\mathrm{f}(\{$ Mansing, Milton $\})\}$

c. 【Sonali Mansing khí Milton-go lak mán-ya $\rrbracket=\exists \mathrm{f}[\forall \mathrm{p}[\mathrm{p} \in\{$ Sonali met $\mathrm{f}(\{$ Mansing, Milton $\})\} \rightarrow \neg$ p]]

Because each set in this derivation is singleton, no alternatives are introduced. The negation operator universally quantifies over a singleton set containing one proposition, as in (31-c). Since the choice function is existentially closed above the level of negation, wide scope is still ensured.

6. Conclusions and prospects. Tiwa lexicalizes disjunction scope: khí lexicalizes a choice function variable, subject to existential closure at a finite clause edge, while $b a$ lexicalizes an alternativeset former, where the alternatives are caught by the closest operator. This raises a question for English, namely, does English lexicalize disjunction scope with two homophonous or's? I assume that the answer to this question is no. For one, it is not necessary in principle to posit this lexical ambiguity to derive or's scopal behavior. As Simons (2005), Brasoveanu \& Farkas (2011) and

\footnotetext{
${ }^{5}$ This is under the assumption that the alternatives cannot compose pointwise with a version of the operator that does not take in a set. See Simons 2005 for an approach to disjunction scope that makes such an assumption through different compositional rules. Because $b a$ cannot take wide scope, positing such an additional compositional rule would lead to the wrong results here. See Charlow 2014 for an alternative way of deriving variable disjunction scope in an analysis that treats disjunctions as alternative-denoting.
} 
Charlow (2014) show, there are ways to derive variable or scope in English with a single lexical item. Further, even if English did lexicalize disjunction scope, the lexical ambiguity could not reflect the same distinction as in Tiwa, as it would make the wrong predictions for the Binder Roof Constraint (examples (20)-(22) above). Instead, the Tiwa data reveal cross-linguistic variation in how wide scope disjunction comes about: while Tiwa uses choice functions to derive wide scope disjunction, English uses alternative means.

\section{References}

Aloni, Maria. 2007. Free choice, modals, and imperatives. Natural Language Semantics 15. 65-94. Alonso-Ovalle, Luis. 2006. Disjunction in alternative semantics: University of Massachusetts Amherst dissertation.

Brasoveanu, Adrian \& Donka Farkas. 2011. How indefinites choose their scope. Linguistics and Philosophy 34(1). 1-55. https://doi.org/10.1007/s10988-011-9092-7.

Charlow, Simon. 2014. On the semantics of exceptional scope: New York University dissertation.

Chierchia, Gennaro. 2001. A puzzle about indefinites. In Carlo Cecchetto, Gennaro Chierchia \& Maria Teresa Guasti (eds.), Semantic interfaces: reference, anaphora and aspect, 51-89. Stanford: CSLI.

Dawson, Virginia. 2018a. A new kind of epistemic indefinite. In Uli Sauerland \& Stephanie Solt (eds.), Proceedings of Sinn und Bedeutung 22, vol. 1 ZASPiL 60, 349-366. Berlin: ZAS.

Dawson, Virginia. 2018b. Outscoping the directive force of imperatives. Ms., UC Berkeley.

Fox, Danny. 2007. Free choice and the theory of scalar implicatures. In Uli Sauerland \& Penka Stateva (eds.), Presupposition and implicature in compositional semantics, 71-120. Palgrave.

Joseph, U.V. 2014. Tiwa-English dictionary with English-Tiwa index. Shillong: Don Bosco Centre for Indigenous Cultures.

Kratzer, Angelika. 1998. Scope or pseudoscope? Are there wide-scope indefinites? In Susan Rothstein (ed.). Events and grammar, 163-196. Dordrecht: Kluwer Academic Publishers.

Larson, Richard K. 1985. On the syntax of disjunction scope. Natural Language and Linguistic Theory 3. 217-264. https://doi.org/10.1007/BF00133841.

Matthewson, Lisa. 1999. On the interpretation of wide-scope indefinites. Natural Language Semantics 7. 79-134.

Matthewson, Lisa. 2004. On the methodology of semantic fieldwork. International Journal of American Linguistics 70(4). 369-415. https://doi.org/10.1086/429207.

Nicolae, Andreea Cristina. 2017. Deriving the positive polarity behavior of plain disjunction. Semantics and Pragmatics 10. 1-21. Early access version. https://doi.org/10.3765/sp.10.5.

Reinhart, Tanya. 1997. Quantifier scope: How labor is divided between QR and choice functions. Linguistics and Philosophy 20(4). 335-397.

Rooth, Mats \& Barbara Partee. 1982. Conjunction, type ambiguity and wide scope "or". In Proceedings of the first West Coast Conference on Formal Linguistics, vol. 1, Linguistics Dept., Stanford University. 
Sauerland, Uli. 2004. Scalar implicatures in complex sentences. Linguistics and Philosophy 27. 367-391. https://doi.org/10.1023/B:LING.0000023378.71748.db.

Schlenker, Philippe. 2006. Scopal independence: a note on branching and wide scope readings of indefinites and disjunctions. Journal of Semantics 23. 281-314.

Schwarz, Benhard. 2001. Two kinds of long distance indefinites. In R. van Rooy \& M. Stokhof (eds.), Proceedings of the Thirteenth Amsterdam Colloquium, 192-197.

Simons, Gary F. \& Charles D. Fennig (eds.). 2017. Ethnologue: Languages of the world, twentieth edition. Dallas, Texas: SIL International. Online edition: http://www.ethnologue.com.

Simons, Mandy. 2005. Dividing things up: The semantics of or and the modal/or interaction. Natural Language Semantics 13. 271-316.

Spector, Benjamin. 2014. Global positive polarity items and obligatory exhaustivity. Semantics and Pragmatics 7. 1-61. https://doi.org/10.3765/sp.7.11.

Weerasooriya, Tharanga. 2017. Deriving specificity, freechoice and ignorance with Q-particles in Sinhala. In Aaron Kaplan (ed.), Proceedings of the 34th West Coast Conference on Formal Linguistics, 572-581. Somerville, MA: Cascadilla Proceedings Project.

Winter, Yoad. 1997. Choice functions and the scopal semantics of indefinites. Linguistics and Philosophy 20. 399-467.

Winter, Yoad. 2002. Flexibility principles in Boolean Semantics: coordination, plurality and scope in natural language. MIT Press. 